\title{
A SEMI-REDUCED FORM EQUATION FOR THE STERLING'S REAL EFFECTIVE EXCHANGE RATE
}

\author{
Partha SEN * \\ University of Michigan, Ann Arbor, MI 48109, USA \\ London School of Economics, London WC2A $2 A E, U K$
}

Received 2 October 1984

This paper derives and estimates a semi-reduced form expression for the UK's real effective exchange rate. The expression was derived following Blanchard and Kahn. Non-linear least squares and non-linear instrumental variables were used in estimation.

This paper derives and estimates a semi-reduced form expression for the real exchange rate and estimates using UK data.

Consider the following model with two assets, money and foreign honds, with wealth effects in the money demand and consumption functions, and sticky prices and agents possessing national expectations:

$$
\begin{array}{r}
M / P+L\left(i^{*}+\epsilon_{t} \mathrm{D} E / E, y,(M+E F) / P\right), \quad L_{1}<0, \quad L_{2}>0, \quad 0<L_{3}<1, \\
y=A\left(Q y / P+i^{*} E F / P, i^{*}+\epsilon_{t} \mathrm{D} E / E-\epsilon_{t} \mathrm{D} P / P,(M+E F) / P\right)+T\left(A, E Q^{*} / Q\right), \\
0<A_{1}<1, \quad A_{2}<0, \quad A_{3}>0, \quad 0<T_{1}<1, \quad T_{2}>0,
\end{array}
$$

where $M=$ money supply, $P=$ price index, $E=$ exchange rate, $y=$ output, $F=$ stock of foreign bonds (assumed positive), $Q=$ price of domestic output, $i^{*}\left(r^{*}\right)=$ the foreign nominal (real) rate of interest, $Q^{*}=$ foreign currency price of the foreign good. D denotes a time derivative $(\equiv \mathrm{d} / \mathrm{d} t)$ and $\epsilon_{t}$ is the expectation of a variable at time $t$.

Eq. (1) is the money market equilibrium condition. Eq. (2) is the goods market equilibrium

\footnotetext{
* I am grateful to Willem Buiter, Marcus Miller and Sushil Wadhwani for comments.
} 
condition. Eq. (3) is a Phillips curve. Eq. (4) gives the accumulation of foreign bonds. Eqs. (5) and (6) define the price index and the foreign real rate of interest respectively.

The model can be reduced to a system of differential equations in three state variables $(m \equiv M / Q$, $C \equiv E / Q$ and $F$ ). Linearising around the long run equilibrium we have

$\mathrm{D} X=A(X-\bar{X})$,

where $X \equiv\left[m, C^{\prime}, f\right]^{\prime}$.

Sufficient conditions for $A$ to have two stable roots are:

(a) $\left(1-A_{1}\left(1+T_{1}\right)\right) Q / P j^{\prime}+A_{2}\left(1+T_{1}\right) P P_{1} Q / P<0$,

which is a requirement that an increase in output should create an excess supply in the goods market,

(b) $\left|T_{1} A_{3} F\right|>\left(1-A_{1}\right) i^{*} F$,

which requires the interest service account to be small, and

(c) $L_{3}$ should be close to unity.

An increase in real balances requires an increase in its rate of change, ceteris paribus (i.e., a fall in the expected rate of inflation). If $L_{3}$ is high then this destabilizing effect is small.

We can then write the semi-reduced form for the real exchange rate following Blanchard and Kahn (1980) (in discrete time) as

$C_{t}=\alpha_{0}+\alpha_{1} F_{t}+\alpha_{2} m_{t}+\alpha_{3} \sum_{i=0}^{\infty} \delta^{i} \epsilon\left(Z_{t+i}(I(t))\right.$,

where $Z_{t}$ are all the exogenous variables and $I(t)$ is the information set at date $t$.

Table $1^{\text {a }}$

\begin{tabular}{lcc}
\hline Parameter & Estimate NLS & Estimate NLIV \\
\hline$\alpha_{0}$ & $-0.0061(-0.51)$ & $-0.0124(-0.56)$ \\
$1 / \delta$ & $1.004(186.78)^{\mathrm{b}}$ & $1.005(159.43)^{\mathrm{b}}$ \\
$\alpha_{1}$ & $-0.824(-14.22)^{\mathrm{b}}$ & $-0.907(-3.80)^{\mathrm{b}}$ \\
$\alpha_{2}$ & $0.429(4.63)^{\mathrm{b}}$ & $0.415(2.32)^{\mathrm{b}}$ \\
$\alpha_{3}$ & $0.00232(3.55)^{\mathrm{b}}$ & $0.00236(3.27)^{\mathrm{b}}$ \\
$E C D$ & $-0.00296(-0.45)$ & $-0.00294(-0.43)$ \\
$M M D$ & $0.00889(1.75)$ & $0.0119(1.28)$ \\
RSS & 0.0135 & 0.0138 \\
SE of regression & 0.0123 & 0.0124 \\
Log likelihood & 289.47 & - \\
$T M$ test & & 2.02 \\
1 st order TR ${ }^{2}$ & 1.94 & 13.87 \\
12th order TR & 17.51 & \\
\hline
\end{tabular}

a Figures in parentheses are $t$-statistics. The number of observations for NLS estimation was 96 and for NLIV it was 95.

$\chi_{1(0.05)}^{1}=3.84, \quad \chi_{12(0.05)}^{2}=21.03$.

Additional instruments for NLIV, $c_{t-2}, c_{t-3}, m_{t-2}, F_{t-2}$. All variables other than $r^{*}, E C D$ and $M M D$ are in logs.

Significant at $95 \%$. 
In this paper we use only one exogenous variable - the foreign real rate of interest. To get a tractable expression for $C_{t}$ we can express it as

$$
\begin{aligned}
C_{t}= & \beta_{0}+\delta^{-1} C_{t-1}+\alpha_{1} F_{t}-\alpha_{1} \delta^{-1} F_{t-1}+\alpha_{2} m_{t}-\alpha_{2} \delta^{-1} m_{t-1}-\alpha_{3} \delta^{-1} r_{t-1}^{*} \\
& +\left(\alpha_{3} \sum_{i=0}^{\infty} \delta^{i} \epsilon\left(r_{t+i}^{*}\left|I(t)-r_{t+i}^{*}\right| I(t-1)\right)\right) .
\end{aligned}
$$

The last term in the parenthesis is the new information which arrived between $t-1$ and $t$ on the time path of the exogenous variables and is uncorrelated with the other right-hand side variables.

We estimated eq. (9) using non-linear least squares (NLS) and non-linear instrument variable (NLIV) methods. We require NLIV if either (a) $F_{t}$ and/or $m$, are not observable contemporaneously, or (b) eq. (8) had a white noise error term which would show up as a moving average error term in (9).

The results are shown in table 1 . Neither of the two dummies one for exchange control and another for monetary targets used were significant ( $E C D$ and $M M D$ respectively). The other coefficients are significant and of the correct sign. The value of $\delta$ is too high, though (almost equal to unity). LM tests were performed for serial correlation/moving average of first and twelfth order and these were found to be absent. The starting values were recovered from OLS estimates. Monthly data from December 1972 to January 1980 was used.

The results are encouraging in view of the fact that the thorough empirical study of the Sterling effective sale by Hacche and Townend (1981) reported inability to explain its behavior by any plausible theoretical model.

\section{References}

Blanchard, O.J. and C.M. Kahn, 1980, The solution of linear difference models under rational expectation, Econometrica 48 , $1305-1311$.

Hacche, G. and J. Townend, 1981, Exchange rates and monctary policy: Modelling Sterling's effective exchange rate, 1972-1980, Oxford Economic Papers 33, 201-247. 